\title{
O BRINCAR NA EDUCAÇÃO INFANTIL: TEORIA E A PRÁTICA DOCENTE
}

\author{
LOPES, Mario Marcos ${ }^{1}$ \\ MAZI, Izabela Maria ${ }^{2}$
}

\begin{abstract}
Recebido em: 2017.08 .07
Aprovado em: 2020.02.11

ISSUE DOI: $10.3738 / 1982.2278 .2847$

RESUMO: Este trabalho tem como finalidade apresentar os resultados de uma pesquisa bibliográfica, que teve como foco a discussão do brincar nas diferentes etapas do desenvolvimento infantil por meio da abordagem de alguns jogos e brincadeiras voltados a primeira etapa da Educação Básica. Procurou-se enfatizar a maneira como crianças se relacionam em seu cotidiano e a forma como interagem socialmente, além de destacar os benefícios proporcionados nos primeiros anos de vida. Com isso, foram levantados aspectos que envolvem o universo lúdico e o cotidiano infantil acerca de alguns teóricos, tanto da Psicologia quando da área educacional. A referida pesquisa aborda ainda, de forma simples, algumas considerações práticas e teóricas acerca dos jogos, brincadeiras e o papel do educador, sujeito fundamental neste processo. Como resultado, foi compreendido a importância do papel do lúdico, as relações sociais advindas desta prática, a construção de conceitos, desenvolvimento integral, além da vivência de maneira significativa frente aos benefícios proporcionados. Desta forma, este estudo proporcionará uma visão e leitura mais consciente acerca do brincar infantil, capaz de formar indivíduos críticos, participativos, e com autonomia perante as dificuldades enfrentadas.
\end{abstract}

Palavras-chave: Jogos. Lúdico. Desenvolvimento Infantil.

\section{PLAYING IN CHILDHOOD EDUCATION: THEORY AND TEACHING PRACTICE}

SUMMARY: This paper presents the results of a bibliographical research that focused on the discussion of playing in the different stages of child development through the approach of games and games aimed at the first stage of Basic Education. We sought to emphasize how children relate to each other in their daily lives and how they interact socially, in addition to highlighting the benefits provided in the early years of life. With this, they were raised that involve the playful universe and the children's daily life on some theorists, both in Psychology and in the educational area. The SECTION discusses, in a simple way, some practical and theoretical considerations about the games, games and role of the educator, fundamental subject in the process. As a result, it was understood the importance of the role of the playful, such as social relations arising from this practice, a construction of concepts, integral development, in addition to experiencing significantly path against the benefits provided. In this way, this study will provide a more conscious vision and a reading about children's play, ability to train critics, participatory and autonomous in face of difficulties faced.

Keywords: Games. Ludic. Child development.

\section{INTRODUÇÃO}

Brincar é uma importante forma de comunicação, é por meio deste ato que a criança pode reproduzir o seu cotidiano. $\mathrm{O}$ ato de brincar possibilita o processo de aprendizagem da criança, pois facilita a construção da reflexão, da autonomia e da criatividade, estabelecendo, desta forma, uma relação estreita entre jogo e aprendizagem.

$\mathrm{Na}$ Educação Infantil entende-se o brincar como um facilitador do desenvolvimento do equilíbrio e das emoções, contribuindo para a formação da personalidade ligando o contexto escolar ao cotidiano infantil.

1 Mestre em Desenvolvimento Regional e Meio Ambiente pela Universidade de Araraquara. Docente do Centro Universitário Barão de Mauá e Faculdade de Educação São Luís. Professor Coordenador na Rede Estadual de Ensino de São Paulo - Diretoria Regional de Ensino de Ribeirão Preto.

${ }^{2}$ Especialista em Psicopedagogia Institucional e Pedagoga pela Faculdade de Educação São Luís. 
Por meio de pesquisa bibliográfica junto às obras dos autores que debatem sobre o tema e documentos emanados do Ministério da Educação foram identificados aspectos que caracterizam os jogos e brincadeiras, apesar do tema ser de ampla discussão na literatura, busca contribuir com os demais trabalhos já realizados, como Kishimoto (2001), Vygotsky (1991), Friedmann (2012) dentre outros. Unindo assim uma breve reflexão entre a teoria e as diferentes atividades práticas em que o professor poderá alicerçar seu trabalho.

Para o educador, a pesquisa colabora no sentido de facilitar sua prática pedagógica, fazendo com que este reflita a função fundamental que há por detrás do brincar, pois por meio da brincadeira a criança descobre o mundo, facilita a socialização e contribui para seu desenvolvimento integral (BRASIL, 1998).

O professor poderá utilizar meios lúdicos para que sua prática pedagógica se efetive da melhor forma possível, pois aquele que media e participa da ação do brincar, estará criando uma situação estimulante e prazerosa, despertando a curiosidade e oferecendo espaço para que a criança desenvolva suas capacidades.

Desse modo, é preciso considerar o brincar como uma ação totalmente significativa e que será na escola o lugar onde o meio social se fecundará no universo infantil, formando sujeitos reflexivos e críticos. Como papel fundamental a escola deve promover a socialização, fazendo com que os brinquedos e as brincadeiras facilitem esta ação. Por fim, este brincar estará promovendo a formação da autonomia e identidade (WALLON, 1981).

Diante do exposto, o referido trabalho tem como objetivo discutir sobre a importância do brincar especificamente na Educação Infantil e a participação do educador como mediador da aprendizagem.

Por fim, no desenvolvimento deste trabalho foram apresentadas diferentes visões de autores ligados ao tema, teorias diversas acerca do desenvolvimento infantil. Este artigo poderá ser fonte de pesquisas, demonstrando e despertando aspectos que ampliam o contexto do brincar para a criança.

\section{O brincar e o jogo em suas concepções}

$\mathrm{Na}$ Educação Infantil o brincar aparece como fonte de estudo e percepções que devem ser levados em conta, já que ocorre um grande aprendizado no momento em que a criança está brincando. A brincadeira e o jogo permanecem em todas as fases do desenvolvimento, onde cada postura é caracteriza pelo desenvolvimento cognitivo. A prática do brincar desenvolve uma aprendizagem reflexiva e significativa, pois é criada uma relação entre o aprender e o brincar.

De acordo com o Referencial Curricular Nacional para a Educação Infantil - RCNEI: 
O principal indicador da brincadeira, entre as crianças, é o papel que assumem enquanto brincam. Ao adotar outros papéis na brincadeira, as crianças agem frente à realidade de maneira não literal, transferindo e substituindo suas ações cotidianas pelas ações e características do papel assumido, utilizando-se de objetos substitutos (BRASIL, 1998, p.27).

Brincar é um meio essencial para a construção da comunicação, pois por meio de reflexões a criança reproduz seu cotidiano vivenciado e este é transformado no imaginário infantil, se desenvolvendo integralmente e facilitando uma aprendizagem significativa e prazerosa (BRASIL, 1998).

Desse modo, o que indica uma brincadeira é o papel que cada um assume no decorrer do brincar, substituição do real pelo imaginário, vivenciado em seu dia a dia por meio do faz de conta. Isto auxilia e favorece uma melhor autoestima, superando inseguranças a serem enfrentadas de forma criativa para a promoção de experiências diversas. A brincadeira também é vista e relacionada a comportamentos naturais e sociais.

Ainda sobre o brincar é apontado pelo RCNEI:

A brincadeira favorece a autoestima das crianças, auxiliando-as a superar progressivamente suas aquisições de forma criativa. Brincar contribui, assim, para a interiorização de determinados modelos de adulto, no âmbito de grupos sociais diversos. Essas significações atribuídas ao brincar transformam-no em um espaço singular de constituição infantil (BRASIL, 1998, p.27).

Jogar e brincar se tornam importantes na medida em que jogos e brincadeiras passam a ser manipulados, possibilitando a formação da identidade, sendo ferramentas fundamentais que proporcionam uma interação lúdica e afetiva.

Em nenhuma brincadeira o desenvolvimento deve estar fechado em um simples final, mas sim na possibilidade de desenvolver e estimular as áreas de aprendizagem, dependendo sempre do estágio em que a criança se encontra, o modo como vive e seu ritmo de vida. Nas brincadeiras há a compreensão de mundo quando se reproduz seu modo de vida, e quando a criança imita tenta compreender o ambiente por ela vivenciado. E durante este brincar aprende por meio da brincadeira a desenvolver raciocínio, julgamentos e a formação de argumentos.

Segundo o RCNEI:

Brincar é uma das atividades fundamentais para o desenvolvimento da identidade e da autonomia. O fato de a criança, desde muito cedo, poder se comunicar por meio de gestos, sons e mais tarde representar determinado papel na brincadeira faz com que ela desenvolva sua imaginação. Nas brincadeiras as crianças podem desenvolver algumas capacidades importantes, tais como a atenção, a imitação, a memória, a imaginação. Amadurecem também algumas capacidades de socialização, por meio da interação e da utilização e experimentação de regras e papéis sociais (BRASIL, 1998, p.22).

O significado do jogo pode ser entendido de várias formas, pois denota diversos objetivos em seu desenvolvimento. Cada jogo possui suas especificações, modo de jogar, regras explícitas 
ou não. Sua representação pode ser apresentada e construída junto à habilidade manual para que assim, o desenvolvimento da criança aconteça. A língua traz a construção das regras, a compreensão da realidade e a manipulação do símbolo. Não é regra obedecer à lógica determinada cientificamente, mas sim respeitar o uso da linguagem levando em conta a interpretação de cada indivíduo inserido no meio social (FRIEDMANN, 2012).

Ainda há uma controvérsia do conceito de jogo, brinquedo e brincadeira. Isso ocorre porque em cada sociedade estas atividades são empregadas de acordo com valores culturais e passados pela linguagem cotidiana. Quando se atribui ao jogo a construção de regras, a estrutura e a sequência são específicas e comuns. São as regras que diferem as características dos jogos quando estão sendo executados, e o passo a passo é construído em uma atividade lúdica.

A reconstrução da imagem da infância é realizada pelo adulto, associado a um valor da sociedade, dependentes de percepções ou memórias de quando era criança. Está implícito o modo como as crianças contemplam a infância, pois ela se expressa por meio do brinquedo que guarda o real, valores, modo de agir e a imaginação de criar o objeto em sua representação de mundo (FRIEDMANN, 2012).

O brinquedo remete a uma referência à infância com representações memoriais e imaginárias, reproduzindo a dimensão do material manipulado, pois sempre dará auxílio à brincadeira que será essencial no imaginário infantil. Na brincadeira as regras são determinadas pela criança e a ação lúdica se concretiza.

Por meio do brinquedo a criança compreende e passa a agir cognitivamente, ela depende do meio externo para internalizar a ação. A imaginação surge nas ideias e não no objeto, a ação domina e cumpre as regras estabelecidas, isso porque ela terá capacidade de entender o significado do objeto e saber o que pretende fazer (KISHIMOTO, 2001).

Não há necessidade de que todos os jogos devam conter regras, isso porque na maioria dos jogos, como o xadrez, a regra está explícita, no faz de conta a criança é quem cria as próprias regras, e elas não necessitam aparecer para que a brincadeira aconteça. Todo jogo ocorre num espaço e tempo sequenciado, já a brincadeira contém características como a liberdade na ação e a decisão do jogador.

As primeiras visões acerca do jogo infantil e da educação são marcadas pela recreação, do uso do jogo dentro do conteúdo escolar, a personalidade infantil e as necessidades para atender a criança.

Historicamente, os jogos e brincadeiras na Antiguidade eram demarcados como relaxamento para se contrapor às atividades que exigiam esforço físico e intelectual, estando assim por muito tempo limitadas à recreação. Já na Idade Média o jogo era visto como "não sério", pois o associavam a jogos de azar, em que muitos apostavam bens valiosos e por vezes 
acabavam perdendo tudo. No Renascimento, ele representava a moral e a ética que estavam contidas nos conteúdos escolares. Era visto como uma ação livre que facilitava e favorecia a inteligência, se adequando às necessidades infantis, e sendo essenciais aos conteúdos ensinados na escola. O professor ficaria responsável em adequar situações lúdicas dentro do conteúdo proposto (KISHIMOTO, 2001).

Segundo Montaigne (1993 apud KISHIMOTO, 2001) o desenvolvimento da linguagem e imaginação caracteriza a função do jogo. Este jogo também designa na expressão espontânea da criança, pois é expressa por meio de sua natureza psicológica. O novo sentimento atribuído à infância caracteriza o Renascimento, onde a criança passa a ser percebida e valorizada em seu desenvolvimento.

Dentro do Romantismo tem-se a perspectiva de que somos dotados de sentimentos e ações expressivas. Sendo assim, o jogo precisa ser pensado para atender as necessidades infantis, pois esta criança brinca e cria espontaneidade em suas ações.

Por meio das regras, a criança tem o poder da fala e com isso pode alterar a brincadeira conforme sua vontade. Quando há a interação e estimulação precoce, a linguagem se desenvolve de forma mais eficaz.

É no momento do jogo e da brincadeira que a criança tenta alcançar meios de resolver suas dificuldades, sejam elas cognitivas, de coordenação motora ou social, onde irá satisfazer seus medos e necessidades, sendo capazes de construir conhecimentos explorando as habilidades que foram adquiridas.

Para a realização da brincadeira a criança necessita de um objeto simbólico, este sendo o brinquedo substituirá o real incorporando o imaginário representado pela criança. Sua estrutura não conterá regras para a utilização, ficando por conta de que criança crie, manipule e desenvolva a brincadeira.

\section{Teoria do Jogo segundo Piaget}

Os primeiros estudos feitos sobre o jogo infantil foram publicados no livro de Piaget (1971) A formação do símbolo na criança, sendo feito ao observar os próprios filhos, onde analisou e interpretou de que forma o pensamento intelectual e o jogo se relacionam e como são pensados pela criança (FRIEDMANN, 2012).

O jogo está relacionado com a construção da inteligência, onde o prazer proporcionado motiva e desperta a aprendizagem. O desenvolvimento humano está relacionado aos jogos, pois surgem nos meses iniciais da criança e o acompanham até a vida adulta.

Jogar também é considerado uma forma educativa nas áreas afetivo-social e psicomotricidade facilitando a construção de valores como o respeito e honestidade. 
Caracterizam-se pela assimilação em aprender a jogar, transferidos em ações apreendidas e no desenvolvimento, aplicando assim o que assimilou na prática.

Com isso o jogo é explicado por Piaget (1971 apud FRIEDMANN, 2012, p.28):

[...] expressão de uma das fases dessa diferenciação progressiva: é o produto da assimilação, dissociando-se da acomodação antes de se reintegrar nas formas de equilíbrio permanece que dele farão seu complemento, no nível do pensamento operatório ou racional [...]. O jogo constitui o pólo extremo da assimilação do real ao eu.

Quando a criança se relaciona em seu meio social estará se adaptando e construindo o conhecimento por meio de sua inteligência. Para melhor compreender a psicologia piagetiana precisamos entender o conceito de assimilação e acomodação. A adaptação é desenvolvida por meio do processo de acomodação e assimilação (PIAGET, 1971 apud FRIEDMANN, 2012).

$\mathrm{Na}$ acomodação a criança molda sua capacidade intelectual e responde aos estímulos do meio externo, por meio de percepções de objetos e movimentos. Na assimilação a criança absorve os elementos externos para sua ação, conduzindo suas condutas, agindo e incorporando o objeto, para que assim possa atender às suas necessidades sejam elas: sociais, biológicas ou psicológicas (FRIEDMANN, 2012).

Os jogos são classificados por categorias de acordo com a faixa etária e as fases do desenvolvimento, sendo os jogos de exercícios, jogos simbólicos e jogos de regras.

Jogos que recebem o nome de "construção" fazem parte dos três tipos e das adaptações de uma fase a outra, é o símbolo transformado internamente, e está na segunda posição entre o segundo e terceiro nível de jogo.

Os jogos de exercícios são os iniciais apresentados à criança quando se encontram no estágio sensório-motor que corresponde à fase de 0 a 1 ano e meio com o surgimento da linguagem. O bebê passa a organizar esquemas de ação e assimilar seu meio, que funcionam como reflexos com o contato direto e imediato. O prazer no gesto está no fazer o movimento e o resultado que ele proporciona. Passa a ter consciência das capacidades adquiridas por meio de novas, e assim serão capazes de usar os jogos e criar novas ações e condutas. Conforme a criança cresce e um objeto é apresentado, a repetição de experimentar os seus sentidos faz com que ela compreenda seu mundo.

Dentro dos jogos de exercícios entram também os do exercício do pensamento. Esses jogos se definem nas combinações de situações sem finalidades, organizando conceitos e combinando palavras. Nas combinações com algum tipo de finalidade as crianças têm o prazer da construção.

O período pré-operatório ocorrendo por volta de 2 a 7 anos, caracterizando os jogos $\underline{\text { simbólicos, onde a inteligência simbólica é construída no estágio anterior. A criança utiliza os }}$ 
mesmos jogos conhecidos, porém com a presença de um símbolo lúdico (objeto ausente que necessita), e passa a construir o faz de conta, por meio de objetos simula e representa um significado ou situação já vivenciados.

Quando a criança se expressa é capaz de assimilar o símbolo e representá-lo de sua maneira. Podendo dramatizar, por exemplo, uma briga presenciada, o cuidar da mãe, os comportamentos observados em casa, entre diversas possibilidades. Esses jogos tem a função de realizar desejos, resolver conflitos que juntados ao prazer levam a uma realidade lúdica ou não.

Nos jogos simbólicos Friedmann (2012, p.35) salienta:

Inicia-se o simbolismo coletivo, com diferenciação e ajustamento de papéis. Mesmo que duas ou mais crianças brinquem de loja, não necessariamente os papéis assumidos são complementares, o que vai se revelar na linguagem - geralmente, monólogos coletivos. A sequência nas ideias deriva dos progressos na socialização. É interessante notar esse círculo de aquisições sociais e mentais no domínio do simbolismo lúdico, tal como se pode assinalá-lo incessantemente no da representação adaptada. Há passagem do egocentrismo inicial para a reciprocidade. No que diz respeito ao simbolismo lúdico, todo o progresso da socialização culmina em sua transformação, no sentido da imitação objetiva do real.

Aos 7 anos deixam o egocentrismo de lado, pois passam a se inserirem nos jogos de regras, separando assim o real do imaginário. No final do estágio simbólico são capazes de desenvolverem construções próximas da realidade e uma melhor cooperação do trabalho coletivo.

Já os jogos de regras substituem os símbolos pelas regras, fazendo relação ao estágio operatório-concreto que vai dos sete aos onze anos. As regras vêm para facilitar as relações sociais onde há a imposição de um grupo.

São desenvolvidas percepções de espaço, tempo, velocidade, ordem, capazes de relacionar os dados reais. Terá habilidade de reverter o pensamento e com isso precisará trabalhar junto à concentração, raciocínio, sorte e atenção. Os jogos agora passarão a conter regras e deverão ser seguidas, cumpridas e respeitadas. Os símbolos são desconstruídos, a criança já não age como antes, começam a aparecer jogos em grupo, o líder e as regras são impostas a todos do grupo.

As regras são explicadas e divididas por Piaget (1971 apud FRIEDMANN, 2012) em quatro estágios: o motor e individual fase de 0 a 2 anos, não há regras coletivas; a egocêntrica que vai de 2 a 5 anos, onde a criança prefere jogar sozinha ou mesmo em grupo e não há regras; a cooperação ou competição, dos 7 aos 10 anos, há a preocupação de vencer o adversário, o divertimento é social e as regras são coletivas, e por fim a codificação das regras correspondente aos 11 e 12 anos onde um código de regras é conhecido e precisa ser seguido por todos.

Entre os 7 e 10 anos: “[...] uma real cooperação é estabelecida, e a partida é regulamentada por leis. Há interesse social e disputa" (FRIEDMANN, 2012, p.38). 
Na teoria piagetiana também é explicado a evolução da prática e da consciência da regra, onde se dividem em três estágios: a anomia, a heteronomia e a autonomia.

Na anomia segundo La Taille, Oliveira e Dantas (1992, p. 49):

[...] Crianças de até cinco anos, seis anos de idade não seguem regras coletivas. Interessam-se, por exemplo, por bolas de gude, mas antes para satisfazerem seus interesses motores ou suas fantasias simbólicas, e não tanto para participarem de uma atividade coletiva.

As normas de conduta são necessidades básicas, as regras obedecidas são cumpridas pelo hábito, onde não está se pensando o certo ou errado, apenas cumprem o que foi proposto.

Já a heteronomia mostra que a criança passa a ter interesse em atividades individuais ou coletivas. Crianças de 9 a 10 anos são capazes de interpretar e modificar as regras, compreender parte delas e entender que carregam uma tradição de gerações. Ela ainda não é capaz de assimilar o sentido e o porquê a regra faz parte do jogo, não as seguindo à risca.

A última fase é a autonomia que contém características contrárias à heteronomia, pois:

[...] correspondem à concepção adulta do jogo. Em primeiro lugar, as crianças jogam seguindo as regras com esmero. Em segundo lugar o respeito pelas regras é compreendido como decorrente de mútuos acordos entre os jogadores, cada um concebendo a si próprio como possível "legislador", ou seja, criador de novas regras que serão submetidas à apreciação e aceitação dos outros. Deve-se acrescentar que a autonomia demonstrada na prática da regra aparece um pouco mais cedo do que aquela revelada pela consciência da mesma (LA TAILLE; OLIVEIRA; DANTAS, 1992, p.50).

Contudo observa-se que a criança utiliza uma lógica de pensar em cada fase de seu desenvolvimento, não podendo deixar que estas passem despercebidas. As idades de cada estágio podem variar, pois as alterações e avanços dependem do meio social ao qual a criança se insere. De acordo com pesquisas os primeiros anos são muito importantes na vida da criança e a escola precisa exercer seu papel que é fundamental nesta etapa do processo.

É necessário olhar a criança de forma plena em relação ao seu desenvolvimento, onde esta descobrirá e construirá seu conhecimento de mundo. Segundo Kishimoto (2001) o desenvolvimento da criança deve ser entendido como um processo global, no brincar a criança está andando, correndo, ou seja, desenvolvendo a sua motricidade paralelamente, é um desenvolvimento social, porque ela brinca com parceiros, com pessoas diferentes, nesse momento ela usa regras, adquire informações, estabelecem relações cognitivas, discute o que julga certo ou errado. 


\title{
Teoria do Jogo segundo Vygotsky
}

$\mathrm{Na}$ teoria sócio-interacionista o jogo é essencial para satisfazer um desejo onde a criança pretende substituir por outro que não se realizou, devendo ser diferente de alguma atividade já praticada por ela.

O brinquedo pode ser considerado como qualquer ferramenta que a criança manuseie para brincar, e o prazer não é o objetivo principal do brinquedo, pois apenas irá satisfazer as necessidades infantis. Com isso Vygotsky (1991, p.73) afirma:

O que é evidente é que a similaridade perceptiva dos objetos não tem um papel considerável para a compreensão da notação simbólica. O que importa é que os objetos admitam o gesto apropriado e possam funcionar como um ponto de aplicação dele.

O brincar se torna importante na vida da criança desde os jogos mais simples até os de regras, que exigirá mais habilidades. O jogo envolve o imaginário criado pela criança onde imaginar é uma ação positiva. Para Vygotsky (1991) não há atividade lúdica sem regras e todo o brinquedo contém regras reais ou não. No brinquedo a regra não precisa aparecer e o brincar ganha arranjos no desenvolvimento. De acordo com Vygotsky (1991, p. 66):

\begin{abstract}
A criação de uma situação imaginária não é algo fortuito na vida da criança; pelo contrário, é a primeira manifestação da emancipação da criança em relação às restrições situacionais. O primeiro paradoxo contido no brinquedo é que a criança opera com um significado alienado numa situação real. O segundo é que, no brinquedo, a criança segue o caminho do menor esforço - ela faz o que mais gosta de fazer, porque o brinquedo está unido ao prazer - e ao mesmo tempo, aprende a seguir os caminhos mais difíceis, subordinados e a regras e, por conseguinte renunciando ao que ela quer, uma vez que a sujeição a regras e a renúncia a ação impulsiva constitui o caminho para o prazer do brinquedo.
\end{abstract}

Estas regras são classificadas em dois tipos: as implícitas e as explícitas. As Implícitas são aquelas que estão ocultas, porém todos as conhecem e as explícitas são as que estão já estabelecidas ou que até mesmo a criança crie no momento da brincadeira.

$\mathrm{Na}$ ação de imitar há uma relação com a realidade, as regras do jogo simbólico são implícitas e a criança pode modificá-las de acordo com a sua intuição. Tentando se conectar com a realidade o lúdico abrange significados de construções de mundo.

Os jogos simbólicos passam a serem jogos de regras e serão as regras que conduzirá o jogo, desse modo a criança assimila conceitos do concreto e real, passando assim a ser um indivíduo social.

No pensamento abstrato a criança não pensará de forma simbólica e agora passará a seguir os jogos de regras. Ao dominar as regras esta detém um comportamento controlado sendo capaz de criar hipóteses e conceitos acerca das situações que lhe forem impostas. 
No faz de conta em que a situação imaginária constitui a brincadeira, a criança escolhe a atividade através do significado do brinquedo. Indo ao encontro da teoria de Vygotsky, em que a criança interage com o significado e com a ideia, e não com o objeto concreto que esta manipula.

O brinquedo facilita uma situação de passagem entre a ação da criança com o objeto concreto e com as suas ações com significados. É observado em:

\begin{abstract}
No final do desenvolvimento surgem as regras, e, quanto mais rígidas elas são, maior a exigência de atenção da criança, maior a regulação da atividade da criança, mais tenso e agudo torna-se o brinquedo. Correr simplesmente, sem propósito ou regras, é entediante e não tem atrativo para a criança. Consequentemente, na forma mais avançado do desenvolvimento o brinquedo, emerge um complexo de aspectos originalmente não desenvolvidos - aspectos que tinham sido secundários ou incidentais no início, ocupam uma posição central no fim e vice-versa (VYGOTSKY, 1991, p.69).
\end{abstract}

Em sua teoria a estrutura do brincar ganha uma nova posição onde o significado dominará o objeto (brinquedo) que é concreto. A ação lúdica não mais será completada a um único fim, mas pelo significado contido detrás do objeto.

O lúdico favorece situações difíceis no decorrer do brincar, pois no imaginário a criança dramatiza papéis e cria um significado próximo ao da situação por ela demonstrada e seu psicológico e realidade mudam por completo.

Quando o significado domina a ação a criança passa a expressar desejos, pois é o grau mais alto em que o desenvolvimento alcança. Também aponta que a capacidade de criar e imaginar leva a desenvolver o pensamento abstrato, porque durante o brincar surgem novas ações, objetos e significados que fazem sentido à criança. Segundo Vygotsky (1991, p.69):

[...] a criação de uma situação imaginária pode ser considerada como um meio para desenvolver o pensamento abstrato. O desenvolvimento correspondente de regras conduz a ações, com base nas quais torna-se possível a divisão entre trabalho e brinquedo, divisão esta encontrada na idade escolar como fator fundamental.

Por meio da aprendizagem das brincadeiras há a interação com o desenvolvimento fazendo com que se ative a Zona de Desenvolvimento Proximal (ZDP), que seria o que a criança faz quando um adulto a intervém sendo ela capaz de realizar a ação sozinha e seu potencial em aprender não será igual ao de outra pessoa. O desenvolvimento real e potencial fazem as interações sociais ser fator central, onde a aprendizagem e o desenvolvimento estão interligados. O brincar despertará aprendizagens que serão partes da função psicológica da criança.

A Zona de Desenvolvimento Proximal é destacado por Vygotsky (1991, p.58): 
Assim, a zona de desenvolvimento proximal permite-nos delinear o futuro imediato da criança e seu estado dinâmico de desenvolvimento, propiciando o acesso não somente ao que já foi atingido através do desenvolvimento, como também àquilo que está em processo de maturação. [...] O estado de desenvolvimento mental de uma criança só pode ser determinado se forem revelados os seus dois níveis: o nível de desenvolvimento real e a zona de desenvolvimento proximal.

Portanto, a teoria sócio interacionista mostra que primeiramente a criança aprende e depois se desenvolve, e caracteriza a importância das brincadeiras e jogos no desenvolvimento infantil. A criança precisa brincar conhecer, descobrir, explorar e interagir para que seu potencial seja desenvolvido. Este brincar desenvolve a linguagem, a função simbólica e os limites do que é concreto e imaginário.

Por fim, promover atividades que envolvam e favoreçam o desenvolvimento infantil como as brincadeiras, em suas situações imaginárias, facilitarão a prática pedagógica. $\mathrm{O}$ brinquedo criará na criança desejos, onde se encaixará nos jogos e em suas regras, as aquisições levarão a níveis simples até o real significado da ação.

\section{Teoria do Jogo segundo Wallon}

De acordo com Wallon (1981) o principal fator na formação da personalidade é o meio social. Ele relaciona a afetividade com a motricidade afirmando serem os responsáveis para o desenvolvimento psicológico de uma criança. A formação da personalidade é gradual, pois a afetividade e a inteligência se integram. Desse modo Wallon $(1981$, p.81) apresenta o conceito de jogo como:

[...] o jogo é o livre inventário e a manifestação destas ou daquelas disponibilidades funcionais. Só há jogo se existir a satisfação de subtrair momentaneamente o exercício duma função às imposições ou às limitações que normalmente ela experimenta de atividades de certo modo mais responsáveis.

$\mathrm{Na}$ afetividade a criança exterioriza seus desejos e a motricidade está na área pedagógica. A inteligência dependerá do meio em que a criança se esconderá e a forma do signo permitirá sua participação na sociedade.

A autonomia e a identidade estão ligadas com o desenvolvimento cognitivo, motor e afetivo, sendo necessários ambientes de aprendizagem que contribuam para que haja experiências de que a criança agregue valores culturais, morais no ambiente social em que vive.

Há diversas discussões acerca da importância do jogo na infância, mas em sua teoria essas concepções são confundidas enquanto a prática do jogo é vista espontaneamente não recebendo assim sua devida utilidade nas disciplinas escolares.

Em sua teoria acerca do jogo Wallon (1981, p.76) afirma que: 
O jogo não é necessariamente o que não exige esforço, [...] porque o jogo pode exigir e fazer libertar quantidades de energia muito mais consideráveis do que as necessárias para uma tarefa obrigatória: estão neste caso certas competições desportivas ou mesmo alguns atos realizados isoladamente, mas livremente.

Em uma atividade lúdica se opõe a função real do jogo quando praticada pela criança, onde as circunstâncias externas dá o poder de alteração e as circunstâncias mentais servem para que se alcance a solução de problemas.

A concepção de jogo é explicada da maneira como o adulto assimilou e foi passado à criança, em sua teoria Wallon (1981) divide os tipos de jogos em quatros fases, de acordo com as etapas do desenvolvimento infantil.

Entretanto podemos dizer que as fases do desenvolvimento são marcadas pelas atividades que são estimuladas e praticadas, por isso a idade de cada ação esperada pode variar de acordo com a socialização da criança em seu meio.

Segundo Wallon (1981, p.81):

O jogo da criança normal, pelo contrário assemelha-se a uma explosão jubilosa ou apaixonada, que tende a experimentar a função em todas as suas possibilidades. [...] Como todo o desenvolvimento pressupõe etapas ulteriores, estas desempenham na criança o mesmo papel que, no adulto, as atividades a respeito das quais, por uma espécie de retrocesso, o jogo pode momentaneamente libertar o exercício das funções tornadas escravas pelo seu uso habitual.

Os jogos funcionais, caracterizados como os mais simples, em que a criança encontra o prazer por meio do som, pela motricidade em realizar movimentos e fazer novas descobertas, desse modo a criança explora o corpo por meio de seus sentidos, quando encontra prazer procura ter novamente a satisfação e o bom efeito que o jogo lhe proporciona.

De acordo com Wallon (1981, p.75) “os jogos funcionais podem ser movimentos muito simples, como estender e dobrar os braços ou as pernas, agitar os dedos, tocar objetos, imprimirlhes balanceamentos, produzir ruídos ou sons".

Por sua vez, os jogos de ficção são aqueles que envolvem atividades lúdicas, o faz de conta, imitações por meio de brinquedos ou dramatizações de papéis de pessoas de seu meio social. Assim, na ficção do jogo:

Com a ficção, introduz-se na vida mental o uso de simulacros, que são a transição necessária entre o indício, ainda ligado à coisa, e o símbolo, suporte das puras combinações intelectuais. Ajudando a criança a transpor este limiar, o jogo desempenha um papel importante na sua evolução psíquica (WALLON, 1981, p.85).

Nos jogos de aquisição a criança passa a conhecer, imitar músicas, imagens, histórias entre outros. Ela se empenha em compreender o mundo à sua volta e reproduzi-lo de sua maneira. 
Os jogos de fabricação são aqueles que a criança entra em contato com a criatividade por meio de atividades manuais de criações, transformações, e improvisos fictícios.

Muitas vezes, os jogos carregam símbolos e trazem benefícios por meio de trocas ou experiências, fazendo com que o prazer seja despertado. O jogo também pode oferecer situações incertas ou inesperadas e a prática dos jogadores tornam-se contínuas.

Em sua teoria Wallon (1981) aponta a imitação vista como o processo em que a criança vivencia e passa por fases diferentes, onde serão a quantidade de ações lúdicas que irão facilitar o progresso e a criança irá internalizar a aprendizagem. Os jogos contribuem para experiências diversas como socialização, memorização entre outras áreas.

Por isso a infância e o lúdico não se separam e a atividade infantil é espontânea e livre. Sendo assim o jogo uma ação voluntária onde o emocional é influenciado, fazendo com que a criança se relacione socialmente no desenvolvimento do jogar.

\section{O educador e o brincar}

O professor no processo do brincar é o responsável por situações de aprendizagem e deve estar atento ao desenvolvimento do aluno e entender quais as contribuições proporcionadas pelas brincadeiras. É importante que o educador em sua prática facilite o ambiente de aprendizagem, para que este possa contribuir e trazer alegria e prazer no ato de brincar.

Segundo o RCNEI (BRASIL, 1998, p.28):

É o adulto, na figura do professor, portanto, que, na instituição infantil, ajuda a estruturar o campo das brincadeiras na vida das crianças. Consequentemente é ele que organiza sua base estrutural, por meio da oferta de determinados objetos, fantasias, brinquedos ou jogos, de delimitação e arranjo dos espaços e do tempo para brincar.

O educador precisa reconhecer o valor educativo proporcionado pelo brincar, pois a brincadeira é uma estratégia de ensino pedagógico, que desenvolve capacidades físicas, emocionais, facilitando a socialização e a formação da personalidade. Deve também ser o mediador da aprendizagem, incluir em sua prática de ensino brincadeiras para que se formem sujeitos participativos, críticos, reflexivos e aptos a enfrentar desafios (FRIEDMANN, 2012).

É necessário saber utilizar os recursos pedagógicos de forma lúdica e que estes façam relação com a aprendizagem. É preciso ainda adequar à aprendizagem ao que se pretende ensinar, o tempo e as intervenções necessárias. Não se deve prender aos instrumentos pedagógicos, onde poderá conduzir um excesso na brincadeira, não possibilitando a liberdade e a criatividade infantil.

Dar oportunidades e criar projetos com espaços lúdicos para os alunos proporciona e possibilita que a criança conviva com as diferenças coletivas e individuais. Essa experiência 
contribuirá e facilitará a transformação do aluno e do grupo social que estes convivem. Segundo Barros (1996) para se desenvolver a autonomia, é preciso que haja um relacionamento de respeito entre o professor e a criança, isso fará com que o aluno aprenda a respeitar a opinião e o ponto de vista do outro.

$\mathrm{Na}$ Educação Infantil o professor é o profissional que deve proporcionar e garantir momentos lúdicos e prazerosos, devendo conduzir com que a exploração de jogos e brincadeiras, sejam efetivas e significativas para a criança.

Segundo Vygotsky (1991) a necessidade da intervenção do educador em possuir métodos e ter objetivos pré-determinados, é essencial para que seu trabalho seja realizado de forma positiva e que este promova a transformação social. E neste processo de ensino e aprendizagem é indispensável a utilização de maneiras diversificadas para trabalhar um mesmo objeto (brinquedo), a fim de se atingir o pensamento lógico.

É preciso que o professor adote posturas para que seus objetivos sejam atingidos de forma eficaz e que o conhecimento seja assimilado pelo aluno. Podemos destacar alguns aspectos importantes a fim de proporcionar bons resultados como oferecer o tempo e o espaço, e materiais para que a brincadeira ocorra de forma livre e espontânea.

Um bom profissional, com uma formação ampla e conhecimentos acerca dos objetivos da Educação Infantil, terá uma excelente contribuição em seu trabalho. Em sua prática educativa a afetividade é um bom caminho para a estimulação, pois é oferecida à criança certa estabilidade emocional para que ela se envolva com o lúdico, e o processo de ensino aprendizagem ocorrerá de forma eficaz para ambos os lados (BARROS, 1996).

Além disso, pode-se, conforme aponta Friedmann (2012):

- Dar espaço a criança se expressar, deixar com que se posicione e que enfatize seus argumentos;

- Estimular a autonomia caso haja conflitos, sendo capaz do controle emocional e compreensão dos envolvidos;

- Nas brincadeiras dirigidas, organizar as regras, deixando com que a criança se envolva e interaja socialmente com as outras;

- Oferecer e estimular ideias sobre as regras, favorecendo a escuta do outro, cooperação, e formação do pensamento lógico;

O educador deve mostrar que cada criança possui um papel que deve ser responsável e cumprir os combinados ou regras. Isso motivará a iniciativa, falar o que pensa ter confiança ao se posicionar, além da estimulação da criatividade.

Nas brincadeiras espontâneas o professor deverá realizar um diagnóstico, onde irá observar e também acabará se envolvendo afetivamente, pois não conseguirá ser objetivo o tempo 
todo. Podem ser feitas intervenções no decorrer dos jogos ou brincadeiras, mas é necessário que se deixe que ocorra naturalmente entre os alunos.

Por muitas vezes a escola assume um papel de heteronomia, regida por leis externas que impõe formas de ensino e práticas pedagógicas pré-determinadas. Onde: “os adultos usam recompensa e punição para controlar o comportamento dos alunos, estão reforçando a heteronomia, que é natural na criança, e impedindo o desenvolvimento de sua autonomia" (BARROS, 1996, p.32).

Nos jogos dirigidos é preciso clareza ao apresentar as regras verbalmente, pois a participação do educador deve ser limitada no caso em que a criança passa a entendê-la ou ser capaz de realizar sozinha. Ele deve orientar a atividade caso surgirem dúvidas, instigando as crianças às dificuldades para que avancem e a aprendizagem se efetive.

A atuação do profissional da educação deve se basear em momentos de observação e interação, como apresentado pelo RCNEI (BRASIL, 1998, p.28):

Por meio das brincadeiras os professores podem observar e constituir uma visão dos processos de desenvolvimento das crianças em conjunto e de cada uma em particular, registrando suas capacidades de uso das linguagens, assim como de suas capacidades sociais e dos recursos afetivos e emocionais que dispõem.

Para a prática de jogos e brincadeiras o professor precisará intervir em determinadas situações. Como no faz de conta mostrado no RCNEI (BRASIL, 1998, p. 49):

\footnotetext{
Para que o faz de conta torne-se, de fato, uma prática cotidiana entre as crianças é preciso que se organize na sala um espaço para essa atividade, separado por uma cortina, biombo ou outro recurso qualquer, no qual as crianças poderão se esconder, fantasiar-se, brincar, sozinhas ou em grupos, de casinha, construir uma nave espacial ou um trem etc.[...] Nesse espaço pode ser afixado um espelho de corpo inteiro, de maneira a que as crianças possam reconhecer-se, imitar-se, olhar-se, admirar-se. Pode-se, ainda, agregar um pequeno baú de objetos de objetos e brinquedos úteis para o faz de conta, que pode ser complementado por um cabideiro contendo roupas velhas de adultos ou fantasias.
}

Com isso, o brincar deverá ser algo permanente em que os interesses da criança apareçam nas diversas faixas etárias. Organizar situações de aprendizagem é fundamental, intervenções diretas auxiliam a criança a ter compreensão de conhecimentos diversos. $\mathrm{O}$ cronograma deve estar baseado na proposta do professor, e principalmente, que a criança ouça e compreenda para a construção de sua experiência.

O professor precisa considerar e organizar seu trabalho levando em conta os conhecimentos prévios do aluno, a individualidade e a diversidade, o grau de dificuldade das atividades e a resolução de problemas como meio de aprendizagens. Também é importante que o 
educador esteja atento às atividades não apenas com o olhar de recreação, mas sim com que estas possuam um fundamento e estejam presentes em seu plano de trabalho pedagógico.

Observar a forma como as crianças brincam é necessário para que se conheçam seus interesses e suas capacidades sejam elas coletivas ou individuais. A maneira como se relaciona com o mundo e com os objetos em sua volta, deve ser a base do trabalho docente. Por meio do comportamento e através do conhecimento das fases do desenvolvimento, o educador saberá quais as posturas e propostas em que deverá trabalhar com a criança.

Desse modo, a intervenção do professor é explicada como:

\begin{abstract}
A intervenção pedagógica provoca avanços que não ocorreriam espontaneamente. A importância da intervenção deliberada de um indivíduo sobre outros como forma de promover desenvolvimento articula-se com um postulado básico de Vygotsky: a aprendizagem é fundamental para o desenvolvimento desde o nascimento da criança. A aprendizagem desperta processos internos de desenvolvimento que só podem ocorrer quando o indivíduo interage com outras pessoas. O processo de ensino-aprendizagem que ocorre na escola propicia o acesso dos membros imaturos da cultura letrada ao conhecimento construído e acumulado pela ciência e a procedimentos metacognitivos, centrais ao próprio modo de articulação dos conceitos científicos (LA TAILLE; OLIVEIRA; DANTAS, 1992, p.33).
\end{abstract}

Quando falamos em atividade lúdica, destaca-se a postura em que o educador deve agir em meio às suas atividades e propostas pedagógicas. Transformar uma atividade em lúdica é saber incorporar a maneira que as crianças expressam suas linguagens, sendo necessário um conhecimento amplo em todas as áreas. Também é preciso que a prática educativa seja capaz de incorporar e criar ambientes motivadores, atividades que envolvam a lógica, ordem, conceitos de leitura, para que os alunos se sintam aptos à resolução de problemas.

No brincar espontâneo, as crianças criam e realizam o brincar livre, pois brincam da maneira como desejam. Para o professor abre a oportunidade de observar as crianças através de suas linguagens de forma expressiva. Além disso, a espontaneidade favorece a criatividade e estimula diversas aprendizagens.

Nos jogos e brincadeiras as crianças irão interagir de acordo com o que o ambiente irá lhe influenciar. Para o educador ao realizar uma atividade lúdica, não se deve estar preocupado apenas com o desenvolvimento desta prática, mas sim com o comportamento e a reação do aluno em ter contato com o novo. Neste ato pedagógico será possível proporcionar ao aluno fantasias, de forma satisfatória, para conduzir sua educação e permitir que este encontre prazer ao praticála.

Além disso, é destacada a questão da autonomia quando: 
Crianças educadas por adultos autoritários têm muito menos oportunidades de desenvolver sua autonomia. Essas crianças são forçadas a obedecer, em vez de serem encorajadas a inventar argumentos que façam sentido e que convençam os adultos. (BARROS, 1996, p.33)

Ao observar o educador pode adquirir diversos aspectos a serem levados em conta como aponta Friedmann (2012):

- O perfil da criança: personalidade, comportamento, gosta de brincar sozinho ou em grupo, as habilidades, dificuldades, interesses, entre outros;

- $\quad$ Como é o social: no conflito, na disputa, na cooperação.

- Possui iniciativa, autonomia, criatividade;

- De que maneira se envolve no jogo: por meio da satisfação, motivação, tensão;

- $\quad$ Assume papéis do decorrer da brincadeira: líder, questionador, mediador;

- Tem raciocínio e argumentação;

- Há interação e troca de ideias;

- Quais as reações apresentadas pela criança;

No brincar dirigido o professor deve agir de maneira mais eficaz com o intuito de atingir objetivos por meio de materiais lúdicos. Ele deve oferecer um tempo, um espaço e bons materiais para que a criança brinque de forma livre.

O professor deve sempre escutar o que as crianças pretendem dizer, estimulando a autoestima e o emocional. Estabelecer regras, não as impondo, pois assim haverá a colaboração e a participação de todos.

Favorecer a troca de ideias é fundamental para chegar a um acordo, isso fará com que as crianças descentralizem suas atenções, colaborando e escutando a ideia do outro.

É preciso que fiquem claras as explicações das regras e das atividades, sendo interessante que o educador participe do jogo inicialmente, com o intuito de apresentar oralmente as ideias. Deve evitar envolver-se nas brincadeiras em que a criança conhece, neste momento o professor deve orientar o desenvolvimento, propondo e estimulando desafios, para que o conhecimento e a aprendizagem sejam assimilados e efetivados.

Também é importante que sejam promovidos momentos de rodas de conversas, em que as crianças irão conversar sobre o jogo ou a brincadeira, representando, se expressando e dando suas opiniões sobre sua experiência.

Quando este educador passa a adquirir estas posturas dentro dos jogos, ele estará atingindo seu papel de educador lúdico. Quando falamos deste professor que é o interventor da aprendizagem, o RCNEI (BRASIL, 1998, p. 30) aponta: 
A intervenção do professor é necessária para que, na instituição de educação infantil, as crianças possam, em situações de intervenção social ou sozinhas, ampliar suas capacidades de apropriação dos conceitos, dos códigos sociais e das diferentes linguagens, por meio da expressão e comunicação de sentimentos e ideias, da experimentação, da reflexão, da elaboração de perguntas e respostas, da construção de objetos e brinquedos, etc. Para isso, o professor deve conhecer e considerar as singularidades das crianças de diferentes idades, assim como a diversidade de hábitos, costumes, valores crenças, etnias etc. das crianças com as quais trabalha respeitando suas diferenças e ampliando suas pautas de socialização. Nessa perspectiva, o professor é mediador entre as crianças e os objetos de conhecimento, organizando e propiciando espaços e situações de aprendizagem que articulem os recursos e capacidades afetivas, emocionais, sociais e cognitivas de cada criança aos seus conhecimentos prévios e aos conteúdos referentes aos diferentes campos de conhecimento humano. Na instituição de educação infantil o professor constitui-se, portanto, no parceiro mais experiente, por excelência, cuja a função é propiciar e garantir um ambiente rico, prazeroso, saudável e não discriminatório de experiências educativas e sociais variadas.

Por isso, cabe ao educador proporcionar momentos de brincadeiras, aprendizagens orientadas, que garantam a troca de experiências e ideias entre as crianças, a fim que de que estas possam demonstrar e se expressar no ato de pensar e agir, no ambiente em que o professor lhe oferecer recursos de aprendizagens. O profissional também deve constantemente refletir sua prática pedagógica, organizando momentos de interação sempre que julgar necessário, garantindo sempre o espaço e a individualidade da criança. A socialização favorece as descobertas, quando o professor promove situações para que realizem atividades coletivas, momentos únicos, desenvolvendo o pensamento, a ação e o estímulo das hipóteses questionadoras.

\section{Jogos e Brincadeiras infantis}

Os jogos e as brincadeiras populares e tradicionais estão envolvidos em diferentes formas de brincar. Muitos fazem parte do folclore, cultura formal, criadas coletivamente por meio da produção espiritual que segundo Friedmann (2012), seria tudo o que é considerado heranças ou que vêm de culturas e valores de um povo, fazendo assim, parte das suas raízes culturais.

Dentre as brincadeiras há as que necessitam de atividade física como barra manteiga, pega-pega e esconde-esconde. Utilizam-se do raciocínio os jogos de cartas e dominó, os de regras variadas como bolinha de gude, de poucas regras como pega ladrão (FRIEDMANN, 2012).

Friedmann (2012) não descreve os jogos simbólicos e os do exercício, pois suas regras podem variar conforme o indivíduo, dependendo assim das ações, momentos lúdicos, e espaços para brincar. Classificando assim as brincadeiras em tradicionais e pós-modernas. Divididas em 13 formas de acordo com as regras, espaço, quantidade de jogadores, se há ludicidade presente na ação e no desenvolvimento do jogo, com a proposta de demonstrar de que maneira a atividade pode ser utilizada pelo educador.

As brincadeiras de perseguir, procurar e pegar, sendo elas jogos de rapidez e agilidade, exigem um grau de esforço físico, pois há liberdade e espaço nos movimentos. O objetivo dessas brincadeiras é alcançar o oponente e vencer, há a inversão de papéis caso necessário. Não precisa 
de objetos para que o desenvolvimento aconteça, para o educador é preciso trabalhar com a rivalidade, onde o aluno deve entender que poderá vencer ou perder. Alguns exemplos são: balança caixão, cada macaco no seu galho, lenço atrás entre outros.

Seguindo sua classificação, após vem os jogos de correr e pular, contendo regras e materiais ajustáveis. Nas corridas há o percurso de ida e volta, contendo vários desafios em seu desenvolvimento, como corrida de sacos, de pneus, com um pé só, de obstáculos. Nos de pular podemos citar a corda, pular sela, elástico etc.

Os jogos de atirar contêm vários desafios e objetivos lançados, como distância, para cima ou dentro de um espaço, sendo possível realizar-se em grupo ou de forma individual, podendo ser amarelinha, bolinha de gude, pião, peteca, jogo de saquinhos.

Há os jogos de agilidade, destreza e força, necessitando de agilidade física e mental para se chegar ao objetivo. São exemplos João bobo, pau de sebo, bambolê, queimada, dança das cadeiras, ioiô. Os de força necessitam de força física do grupo para definirem a competição, como queda de braço, briga de galo, cabo de guerra.

Nas brincadeiras de roda as crianças precisam de uma música para cantar, fazerem rimas, virarem-se, dançarem, girarem todos em um mesmo ritmo, conhecidas como escravos de Jó, ciranda, que horas são etc.

Os jogos de cócegas são dirigidos por uma criança em seu estágio sensório- motor ou um adulto, para que o corpo possa ser explorado pelos movimentos. Alguns deles são toicinho, mindinho, gato xadrez e outros.

As brincadeiras ou jogos de adivinha e pegas precisam de reflexão, ação física para correr, e podem ser a forca, passa anel, tá quente/tá frio, quem está diferente. Alguns de pegas são Terezinha de Jesus, vaca amarela, enganei o bobo.

Já os jogos de representação são os que ocorrem por meio de um diálogo geralmente memorizado, de histórias ou fatos específicos e seguido de uma mímica. Podem ser a própria mímica, marcha-soldado, elefante voa.

Entra-se nas brincadeiras de faz de conta aquelas em que as crianças procuram reproduzir papéis e comportamentos de pessoas à sua volta. Há a presença ou não de objetos, sempre há ações imaginárias da criança com o meio. Não existe uma classificação segundo Friedmann (2012) para este tipo de brincadeira, pois é a criança quem cria a regra e a situação, são exemplos: casinha, boneca, escolinha, super-heróis entre vários outros. Essas ações imaginárias são fundamentais para o desenvolvimento infantil, pois facilitam o desenvolvimento cognitivo, social, afetivo, físico, promovem a criatividade e faz com que o professor tenha um diagnóstico de como o aluno conhece a sua realidade. 
Os jogos com brinquedos construídos fazem com que a criança construa uma atividade lúdica por meio do brinquedo. Exemplos são a pipa, perna de pau, barquinho de papel.

As brincadeiras de salão ocorrem em ambientes fechados, pois necessitam de esforço e habilidade mental, se realizam de forma coletiva, com o auxílio ou não de objetos, um bom exemplo seria a mímica. Além disso, há jogos de amor e jogos verbais ou corporais, onde há a presença de amor e amizade, como o correio elegante, telefone sem fio, beijo, abraço, aperto de mão.

Por fim, o jogo classificado por Friedmann (2012) são os jogos de mesa, vistos como prática coletiva onde as regras se baseiam em tabuleiros, competições em equipes ou individualmente, são eles o truco, bingo com números e o baralho.

\section{A eficácia dos jogos e brincadeiras}

A seguir como proposto pela teoria de Friedmann (2012) acerca dos jogos foram realizadas classificações de diversas brincadeiras, a fim de destacar a importância, as inúmeras áreas e possibilidades.

\section{Amarelinha}

Pode ser realizada com 2 ou mais participantes;

Começa-se a fazer um traçado no chão e cada criança pula em sua vez. Ela deve jogar uma pedra pequena dentro de cada quadrado com números desenhados, a começar pelo número 1 . Quando a pedra estiver em um quadrado, não se deve pisar dentro, segue-se pulando até o último número e na volta pega-se a pedra. Se caso a criança pisar na linha ou a pedra cair fora do quadrado, ela perderá sua vez.

Dentro desta brincadeira está presente fatores que possibilitam as áreas do desenvolvimento da criança.

Área Afetiva

- Facilita o controle emocional, pois a criança deverá saber esperar sua vez e facilitará o autocontrole.

Área Cognitiva

○ Promoverá noções matemáticas, como numerais, ordem para jogar e pular.

○ Terá noção de espaço (começo, meio e fim).

Área da Criatividade

○ Desenvolverá a criatividade, aprenderá sobre regras simples e o espaço permitido.

Área Físico Motora

○ Será capaz de pular de forma alternada com um pé só ou dois. 
Área Social

○ $\quad$ Entenderá o que é competição e que precisará respeitar o outro.

\section{Dança das cadeiras}

Pode ser realizada com 3 ou mais participantes.

Deve-se pegar certo número de cadeiras, de acordo com a quantidade de jogadores, menos uma cadeira que irá faltar. Organiza-se as cadeiras de costas por meio de fileiras ou em círculo, e os participantes devem ficar em volta à elas. Coloca-se uma música para tocar, enquanto todos rodeiam em volta das cadeiras. Quando a música para, cada uma deve sentar na cadeira que está próximo e aquele quem ficar de pé é eliminado. Segue-se tirando uma cadeira em cada rodada, e a brincadeira continua. Vencerá quem conseguir sentar até a última rodada, na única cadeira que sobrar.

\section{Área Afetiva}

- A criança terá de se conter quando uma cadeira for tirada, e até mesmo, poderá se frustrar ao perder tendo que sair.

Área Cognitiva

○ Desenvolvimento da atenção;

○ $\quad$ Noção de espaço, para entender que sempre haverá uma cadeira a menos.

Área Físico Motora

○ Desencadeia a coordenação auditiva e motora, quando a música parar, deve-se sentar.

Área Social

○ Incentivo para que se ganhe por meio da competição e atenção na brincadeira.

\section{Mímica}

Jogam-se 2 ou mais participantes.

Um dos jogadores se gesticula ou se expressa por meio de gestos, um filme, animal, música, comida etc. Divide-se em equipes, revezando um por vez para apresentar a mímica, conforme cada jogador for acertando.

Área Afetiva

○ Controle emocional e paciência em esperar sua vez e a do outro.

Área Cognitiva

- Desenvolve o nível do conhecimento usados em diversas áreas, com o intuito de adquirir novas informações, estimulando o pensamento abstrato.

Área de Linguagem

○ Ampliação do vocabulário por meio dos sinônimos da palavra. 


\section{Área Físico Motora}

○ Por meio dos gestos realizados pelo corpo e expressões passadas.

\section{Área Social}

○ Desperta a cooperação em trabalhar em grupo, pois quem vence é a equipe;

○ Favorece também a integração com novas crianças.

\section{CONSIDERAÇÕES FINAIS}

Este trabalho teve como objetivo apresentar um estudo acerca dos jogos e brincadeiras, especificamente o brincar em suas diversas finalidades e importância para com crianças da Educação Infantil.

Identificou-se de forma detalhada aspectos que envolvem as brincadeiras, jogos, sejam eles realizados de forma espontânea ou dirigida. Foram pesquisados ideias e pontos de vista tanto nas áreas de Educação e Psicologia.

Ao longo do trabalho identifica-se que, a criança sempre aprende no momento em que se brinca, pois, a brincadeira está presente no cotidiano infantil em todas as fases do desenvolvimento. Com isso, destaca-se o estabelecimento de vínculos no ato do brincar, porque a criança irá depositar todas suas emoções, angústias, medos, e sempre estarão se envolvendo de forma significativa com o meio social.

Em segundo momento foi enfatizado a influência do professor enquanto mediador da aprendizagem. Ele sempre deve considerar a criança em seu pleno desenvolvimento, sem deixar de perder nenhuma dessas fases. É preciso conhecer a criança como alguém que pensa e sente o mundo de sua própria maneira. Por meio do faz de conta ela conhece e compreende o mundo a sua volta, onde convivem com relações e condições de vida diferentes. Além disso, são desenvolvidas capacidades de imaginação, imitação, atenção e memória.

O educador deve direcionar, ou também deixar com que a brincadeira ocorra de forma espontânea. O professor também será o facilitador da aprendizagem, pois promoverá com que a criança construa sua autonomia.

Por fim, é necessário que o mediador compreenda que sua intervenção é fundamental, por meio de observações, expondo materiais pedagógicos adequados, espaço, tempo, planejando com que outras áreas como a socialização e linguagem participem e sejam efetivadas neste brincar infantil. 


\section{REFERÊNCIAS}

BARROS, C. S. G. Psicologia e Construtivismo. São Paulo: Ática, 1996.

BRASIL. Referencial Curricular Nacional para a Educação Infantil. Ministério da Educação e do Desporto, Secretaria de Educação Fundamental. Brasília: MEC/SEF, 1998.

FRIEDMANN, A. O brincar na Educação Infantil - observação, adequação e inclusão. São Paulo: Moderna, 2012.

KISHIMOTO, T. M. Jogo, brinquedo, brincadeira e educação. São Paulo: Cortez, 2001.

KISHIMOTO, T. M. O brincar e suas teorias. São Paulo: Cengage Learning, 2014.

LA TAILlE, Y; OlIVEIRA, M. K; DANTAS, H. Piaget, Vygotsky, Wallon: teorias psicogenéticas em discussão. São Paulo: Summus, 1992.

VYGOSTKY, L. S. A formação social da mente. 4.ed. São Paulo: Martins Fontes, 1991.

WALLON, H. A evolução psicológica da criança. Lisboa: Edição 70, 1981. 